Egyptian

Orthodontic Journal

\title{
RELIABILITY OF CEPHALOMETRIC MEASUREMENTS UTILIZED IN EVALUATION OF THE VERTICAL FACIAL DIMENSION
}

\author{
Mahasen Taha ${ }^{1}$ and Mona A Montasser ${ }^{2}$
}

\section{ABSTRACT:}

Objectives: the objective of the current study was to assess the reliability of five vertical cephalometric measurements. Materials and Methods: The study used 40 digital lateral cephalographs of subjects with skeletal class 1, accepted normal occlusion, and balanced profile. Each cephalograph was traced and five measurements for evaluating the vertical facial dimension were used; (1) FMA angle, (2) SN-MMP angle, (3) $\Upsilon$-axis angle, (4) $\mathcal{L} F \mathcal{H} / \mathcal{T F H}$, and (5) PFH/TFH. The data was tested for normality and correlations were tested. Results: There were no differences between the female and male groups for the five measurements. All five measurements did not show systematic errors and the casual errors were all almost within 1 measurement unit. Results showed moderate to high correlation between FMA and both $S \mathcal{N}-\mathcal{M P}(r=0.52)$ and $\mathcal{Y}$-axis angle $(r=0.57)$ while LFH/TFH showed moderate to high correlation with both PFH/TFH $(r=0.59)$ and SN-MMP $(r=0.60)$. Conclusions: FMA and $\mathcal{L F H} / \mathcal{T F H}$ showed more symmetrical and better clustering of the measurements. All five measurements showed causal errors within acceptable clinical level. The results suggest that FMA is better confirmed by other angular measurements; LFH/TFH and

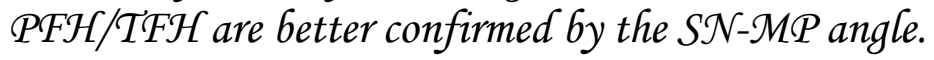

1- Associate professor of Orthodontics, Orthodontic Department - Faculty of Dentistry University of Mansoura

2- Lecturer of Orthodontics, Orthodontic Department - Faculty of Dentistry - University of Mansoura 
Egyptian

Orthodontic Journal

\section{INTRODUCTION}

Since it was introduced by Broadbent ${ }^{1}$ in 1931, cephalometric radiography has been used largely in orthodontic research and treatment basically in diagnosis, treatment planning, treatment evaluation, and growth prediction. ${ }^{2}$ Whatever is the use, it is important to know the degree of accuracy of the cephalograph measurements and the sources of errors.

Magnification and distortion could limit the accuracy of conventional lateral cephalograph; the most significant weakness is the fact that it is a two dimensional representation of a three dimensional structure. Structures are displaced vertically and horizontally in proportion to their distance from the film or recording plane. ${ }^{3}$ Two-dimensional cephalometric norms cannot be readily used for three-dimensional measurements because of the projection errors. ${ }^{4}$ Random errors in cephalometric analysis include errors in tracing, landmark identification, and measurements, ${ }^{5}$ many factors influence accurate identification of cephalometric landmarks as distinctness of anatomic detail, noise from adjacent structures, conceptual judgment based on past knowledge and experience of the investigator. ${ }^{6-8}$ As early as 1971 Baumrind and Frantz ${ }^{9,10}$ presented two studies on the reliability of cephalometric head film measurements including reliability of landmarks and angular and linear measurements, followed by a study in 1976 by Baumrind et $\mathrm{al}^{11}$ on the reliability of cephalometric head film measurements in tracing superimposition. Validity and reliability of cephalometric measurements have been an area of research scrutinizing over the years. ${ }^{6,12-19}$

Errors of projection in cephalometric measurements are unavoidable unless three dimensional measurements are used however; errors in drawing lines and planes and measuring lines and angles with hand instruments could be eliminated with the use of computer programs. ${ }^{10,20}$ Attempts have been made to eliminate errors of landmarks identification by giving precise definition of the landmarks and stressing high cephalometric image quality, but the process of landmarks identification is a subjective process and therefore errors are unavoidable and those errors consequently will influence the linear and angular measurements. ${ }^{10}$

Three factors determine the impact of error in identification of a specific landmark on the linear and angular values involving that landmark; first the actual magnitude of the error involved in identifying 
Egyptian

Orthodontic Journal

the specific landmark; second the linear distance between the point representing the landmark and the points representing the other landmarks with which it is connected for a certain measure; third the direction from which the line segment between two landmarks intersects the envelope of error of each landmark. ${ }^{10}$ Therefore, studies have shown large differences in the reliability of identification among different landmarks. ${ }^{5,10,21}$

The objective of this study was to evaluate the reliability of five cephalometric measurements of the vertical facial dimension.

\section{MATERIALS AND METHODS}

The study used 40 digital lateral cephalographs of subjects, comporising 20 females and 20 males, with age range from $19-22$ years. The inclusion criteria for the subjects included(1) Skeletal Class 1, (2) accepted normal occlusion, and(3) accepted balanced profile, (4) no previous history of orthodontic treatment. Subjects were undergraduate students in College of Dentistry- Mansoura University who were invited to participate in the study by the authors and a cephalograph was taken after their consent to participate.

All films were traced and landmarks were identified, reference points and planes were located, linear and angular measurements were taken. Eight landmarks and five measurements ${ }^{22}$ for evaluating the vertical facial dimension (Figure1) were used in this study; (1) FMA angle: the angle between Frankfort horizontal plane (FH) and Mandibular plane (MP), (2) SN-MP angle: the angle between SN plane and the Mandibular plane (MP), (3) Y-axis angle: the angle between Frankfort horizontal plane (FH) and S-Gn plane, (4) LFH/TFH: the lower face height (ANS-Me) divided by the total face height (N-Me) in percent, (5) PFH/TFH: the posterior face height (S-Go) divided by the total face height $(\mathrm{N}-\mathrm{Me})$ in percent.

Systematic errors were evaluated with dependent t-tests at a significance level of 5\%. Casual errors and reliability of the measurements were tested using Dahlberg's formula $\left(\mathrm{Se}^{2}=\sum \mathrm{d}^{2} / 2 \mathrm{n}\right)$ where $\left(\mathrm{Se}^{2}\right)$ is the error variance and (d) is the difference between two determinations of the same variable. 
Statistical comparison of the two groups was performed with independent samples t-test. Based on the results of the t-test, the whole data of the two groups was combined into a single group. Descriptive statistics, including mean, standard deviation, median, interquartile range, skewness, kurtosis, and minimum and maximum values for all measurements were calculated. Skewness and Kurtosis are measures of the distribution of the values of each measure. Skewness refers to the "lean" of a distribution therefore, it is a measure of symmetry while, Kurtosis refers to the "flatness" of a distribution therefore, it is a measure of the extent to which observations cluster around a central point. In both of the tests the closer the value to zero, the more close the distribution to normal, values not between -2 and +2 indicate that the data is too far away from a normal distribution.

Testing the normality of data distribution in the current study was done with Shapiro-Wilk test and Kolmogorov-Smirnov test. Pearson correlations were examined for interrelationships between measurements. All calculations and tests were carried out using Statistical Package for Social Sciences (SPSS Inc, Chicago, Illinois, USA) program version 10. Confidence level was set at 0.05 .

Table 1. Cephalometric landmarks and planes

\begin{tabular}{|l|l|}
\hline \multicolumn{1}{|c|}{$\begin{array}{c}\text { andmarks } \\
\text { and Planes }\end{array}$} & \multicolumn{1}{c|}{ Definition } \\
\hline S & Sella: center of pituitary fossa \\
\hline N & Nasion: most anterior aspect of frontonasal suture \\
\hline ANS & Anterior nasal spine: most anterior aspect of anterior nasal spine \\
\hline Me & Menton: most inferior point of chin on outline of symphysis \\
\hline Gn & $\begin{array}{l}\text { Gnathion: point midway between pogonion and menton on outline of } \\
\text { symphysis }\end{array}$ \\
\hline Pog & Pogonion: most anterior point of symphysis \\
\hline Go & Gonion: most posterior and inferior point on outline of mandibular angle \\
\hline Or & Orbitale: lowest point on the inferior border of the orbit \\
\hline Po & Porion: most superior point on the external auditory meatus (anatomical point) \\
\hline MP & Mandibular plane: Go-Me plane \\
\hline FH plane & Frankfort plane: Or-Po plane \\
\hline Y-axis plane & Y-axis plane: S-Gn plane \\
\hline
\end{tabular}

Volume 41 - June 2012 
Figure 1. Cephalometric landmarks and planes

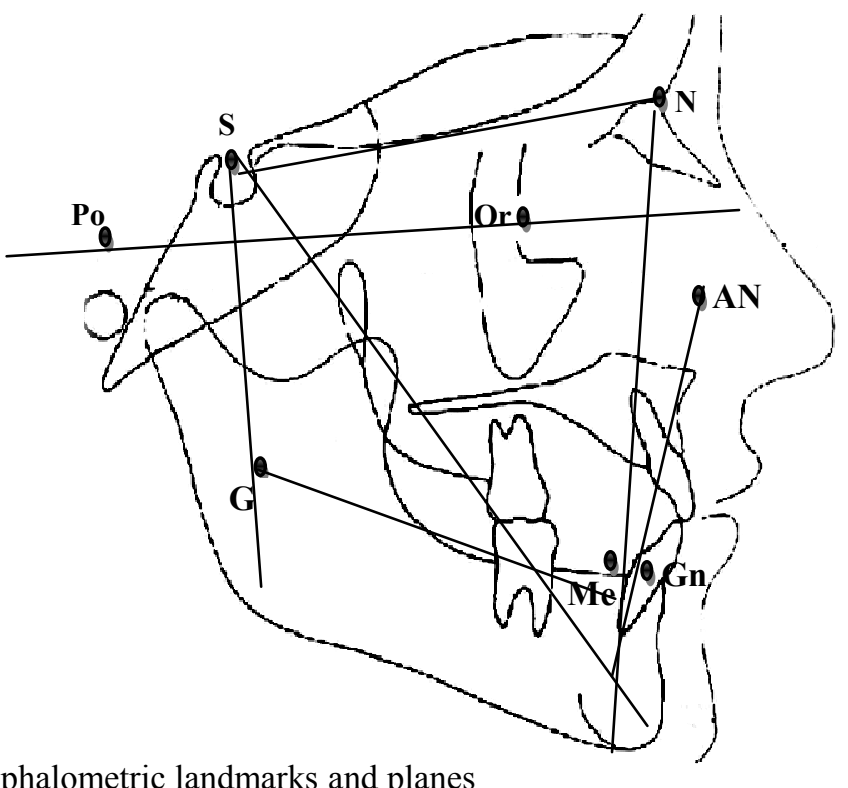

\section{RESULTS}

Descriptive statistics for the five vertical dimension measurements, distributed between males and females, including mean and standard deviation and the results of t-test are shown in Table 2 . The study error tests showed no systematic errors (Table 3 ) and casual errors around 1 degree and 1 percent error (Table 4).

Descriptive statistics for the five vertical dimension measurements, for the total sample, including mean, standard deviation, median, interquartile range, skewness, kurtosis, and minimum and maximum values are shown in Table 5. The results of the tests of normality (Kolmogorov-Smirnov and Shapiro-Wilk) are presented in Table 6. Results of Pearson correlation coefficients are presented in Table 7.

The Histograms and Q-Q plots of the five measurements are illustrated in Figure 2 and Figure 3. The FMA showed the highest frequencies for the central values between $27.0^{\circ}$ and $29.0^{\circ}$ which is a range very close to the mean found to be $27.28^{\circ} \pm 2.93^{\circ}$. The $\mathrm{Q}-\mathrm{Q}$ probability plots (Figure 3 ) showed close distribution of the data around the straight line. The LFH/TFH showed normal distribution of the data with the highest frequencies for the values between 57.5 percent and 58.5 
percent whereas the mean was $58.60 \pm 1.73$ percent. The Q-Q probability plots (Figure 3) showed close distribution of the data around the straight line. The histograms for the Y-axis data (Figure 2) showed slight skewness to the left with the highest frequencies for the central values between $63.0^{\circ}$ and $65.0^{\circ}$ whereas the mean was $62.55 \pm 2.49^{\circ}$. The Q-Q probability plots (Figure 3) showed normal distribution of the data as indicated by the distribution of the values around the straight line. The histograms for the SN-MP angle (Figure 2) showed skewness to the right with the highest frequencies for the central values between $33.0^{\circ}$ and $35.0^{\circ}$ whereas the mean was $33.0^{\circ} \pm 2.11^{\circ}$. The Q-Q probability plots (Figure 3) showed less clustering of the data around the straight line. The histograms for the PFH-TFH (Figure 2) showed slight skewness to the left with the highest frequencies for the values between 61.0 percent and 63.0 percent whereas the mean was $62.64 \pm 3.18^{\circ}$. The Q-Q probability plots (Figure 3 ) showed the least clustering of the data around the straight line

Table 2. Descriptive statistics and t-test for the five vertical dimension measurements distributed as males and females

\begin{tabular}{|c|c|c|c|c|c|c|}
\hline \multicolumn{2}{|c|}{ Gender } & $\mathbf{N}$ & Mean & Std. Deviation & $\mathbf{t}$ & $\mathbf{P}$ \\
\hline \multirow{2}{*}{ FMA } & Male & 20 & 26.8500 & 3.45307 & \multirow{2}{*}{0.92} & \multirow{2}{*}{0.37} \\
\hline & Female & 20 & 27.7000 & 2.29645 & & \\
\hline \multirow{2}{*}{ SN-MP } & Male & 20 & 32.9500 & 2.62528 & \multirow{2}{*}{0.15} & \multirow{2}{*}{0.88} \\
\hline & Female & 20 & 33.0500 & 1.50350 & & \\
\hline \multirow{2}{*}{ Y-axis } & Male & 20 & 62.6500 & 2.66112 & \multirow{2}{*}{0.25} & \multirow{2}{*}{0.80} \\
\hline & Female & 20 & 62.4500 & 2.37254 & & \\
\hline \multirow{2}{*}{ LFH/TFH } & Male & 20 & 58.5025 & 2.04426 & \multirow{2}{*}{0.34} & \multirow{2}{*}{0.74} \\
\hline & Female & 20 & 58.6899 & 1.38329 & & \\
\hline \multirow{2}{*}{ PFH/TFH } & Male & 20 & 63.3626 & 4.23191 & \multirow{2}{*}{1.45} & \multirow{2}{*}{0.15} \\
\hline & Female & 20 & 61.9216 & 1.32059 & & \\
\hline
\end{tabular}

Table 3. Paired t-test

\begin{tabular}{|c|c|c|c|}
\hline & \multicolumn{3}{|c|}{ Casual error } \\
\cline { 2 - 4 } & Female & Male & Total \\
\hline FMA & 0.71 & 0.95 & 0.84 \\
\hline SN-MP & 0.71 & 0.95 & 0.84 \\
\hline Y-axis & 1.05 & 0.95 & 1.00 \\
\hline LFH/TFH & 0.76 & 0.81 & 0.78 \\
\hline PFH/TFH & 0.43 & 0.54 & 0.49 \\
\hline
\end{tabular}


Table 4. Casual errors for the five vertical dimension measurements

\begin{tabular}{|c|c|c|c|c|}
\hline \multirow{4}{*}{} & Pair 1 & FMA - FMA-RE & t & P \\
\cline { 2 - 5 } & Pair 2 & SN-MP - SN-MP-RE & $-.408-$ & $.704 \cdot$ \\
\cline { 2 - 6 } & Pair 3 & Y-AXIS - Y-AXIS-RE & -0.272 & $.799 \cdot$ \\
\cline { 2 - 6 } & Pair 4 & PFH/TFH - PFH/TFH-RE & -0.202 & $.850 \cdot$ \\
\cline { 2 - 6 } & Pair 5 & LFH/TFH - LFH/TFH-RE & $.165 \cdot$ & $.877 \cdot$ \\
\hline \multirow{5}{*}{ MALE } & Pair 1 & FMA - FMA-RE & 1.000 & $.374 \cdot$ \\
\cline { 2 - 6 } & Pair 2 & SN-MP - SN-MP-RE & 1.000 & $.374 \cdot$ \\
\cline { 2 - 6 } & Pair 3 & Y-AXIS - Y-AXIS-RE & -0.302 & $.778 \cdot$ \\
\cline { 2 - 6 } & Pair 4 & PFH/TFH - PFH/TFH-RE & $.770 \cdot$ & $.484 \cdot$ \\
\cline { 2 - 6 } & Pair 5 & LFH/TFH - LFH/TFH-RE & -1.029 & $.362 \cdot$ \\
\hline
\end{tabular}

Table 5. Descriptive statistics for the five vertical dimension measurements

\begin{tabular}{|c|c|c|c|c|c|c|}
\hline & & \multicolumn{5}{|c|}{ Measurements } \\
\hline \multicolumn{2}{|l|}{ Statistics } & FMA & SNA-MP & Y-axis & LFH/TFH & PFH/TFH \\
\hline \multicolumn{2}{|l|}{ Mean } & 27.28 & 33.00 & 62.55 & 58.60 & 62.64 \\
\hline \multirow{2}{*}{$\begin{array}{l}\text { 95\% Confidence Interval } \\
\text { for Mean }\end{array}$} & Lower Bound & 32.32 & 61.75 & 58.04 & 61.63 & 61.63 \\
\hline & Upper Bound & 33.68 & 63.35 & 59.15 & 63.66 & 63.66 \\
\hline \multicolumn{2}{|c|}{ 5\% Trimmed Mean } & 27.31 & 33.25 & 62.58 & 58.59 & 62.43 \\
\hline \multicolumn{2}{|l|}{ Median } & 27.00 & 33.00 & 62.50 & 58.33 & 62.45 \\
\hline \multicolumn{2}{|l|}{ Variance } & 8.56 & 4.46 & 6.20 & 2.98 & 10.11 \\
\hline \multicolumn{2}{|c|}{ Std. Deviation } & 2.926 & 2.11 & 2.49 & 1.73 & 3.18 \\
\hline \multicolumn{2}{|l|}{ Minimum } & 20.00 & 25.00 & 57.00 & 55.30 & 56.92 \\
\hline \multicolumn{2}{|l|}{ Maximum } & 33.00 & 36.00 & 67.00 & 61.90 & 73.48 \\
\hline \multicolumn{2}{|l|}{ Range } & 13.00 & 11.00 & 10.00 & 6.60 & 16.56 \\
\hline \multicolumn{2}{|c|}{ Inter quartile Range } & 4.50 & 2.75 & 3.75 & 2.58 & 3.10 \\
\hline \multicolumn{2}{|l|}{ Skewness } & -0.07 & -1.93 & .12 . & 0.08 & 1.32 \\
\hline \multicolumn{2}{|l|}{ Kurtosis } & 0.07 & 5.38 & -0.38 & -0.48 & 2.73 \\
\hline
\end{tabular}


Egyptian

Orthodontic Journal

Table 6. Tests for normality of data distribution for the five vertical dimension measurements

\begin{tabular}{|c|c|c|c|c|c|c|}
\hline & \multicolumn{3}{|c|}{ Kolmogorov-Smirnov } & \multicolumn{3}{c|}{ Shapiro-Wilk } \\
\cline { 2 - 7 } & Statistic & df & Sig. & Statistic & df & Sig. \\
\hline FMA & 0.16 & 40 & 0.01 & 0.97 & 40 & 0.26 \\
\hline SN-MP & 0.23 & 40 & 0.000 & 0.81 & 40 & 0.000 \\
\hline Y-axis & 0.10 & 40 & $0.20^{*}$ & 0.96 & 40 & 0.14 \\
\hline LFH/TFH & 0.11 & 40 & $0.20^{*}$ & 0.97 & 40 & 0.44 \\
\hline PFH/TFH & 0.19 & 40 & 0.001 & 0.90 & 40 & 0.00 \\
\hline
\end{tabular}

Table 7. Pearson correlation coefficients between the five vertical dimension measurements

\begin{tabular}{|c|c|c|c|c|c|c|}
\hline & & FMA & SN-MP & Y-AXIS & LFH/TFH & PFH/TFH \\
\hline \multirow{3}{*}{ FMA } & Pearson Correlation & 1 & $.52^{* *}$. & $.57^{* *}$. & $0.34^{*}$ & -0.28 \\
\hline & Sig. (2-tailed) & - & $.001 \cdot$ & .000 & $.03 \cdot$ & .08 • \\
\hline & $\mathbf{N}$ & 40 & 40 & 40 & 40 & 40 \\
\hline \multirow{3}{*}{ SN-MP } & Pearson Correlation & $0.52^{* *}$ & 1 & 0.26 & $0.49^{* *}$ & $-0.60^{* *}$ \\
\hline & Sig. (2-tailed) & .001 & - & 0.10 & .001 & .000 \\
\hline & $\mathbf{N}$ & 40 & 40 & 40 & 40 & 40 \\
\hline \multirow{3}{*}{ Y-axis } & Pearson Correlation & $0.57^{* *}$ & 0.26 & 1 & 0.01 & 0.04 \\
\hline & Sig. (2-tailed) & .000 & .10 & - & 0.96 & 0.81 \\
\hline & $\mathbf{N}$ & 40 & 40 & 40 & 40 & 40 \\
\hline \multirow{3}{*}{ LFH/TFH } & Pearson Correlation & $0.34^{*}$ & $.49^{* *}$ & $.01 \cdot$ & 1 & $-0.59^{* *}$ \\
\hline & Sig. (2-tailed) & 0.03 & .001 & 0.96 & - & 0.000 \\
\hline & $\mathbf{N}$ & 40 & 40 & 40 & 40 & 40 \\
\hline \multirow{3}{*}{ PFH/TFH } & Pearson Correlation & -0.28 & $-0.60^{* *}$ & 0.04 & $-0.60^{* *}$ & 1 \\
\hline & Sig. (2-tailed) & 0.08 & .000 & .81 & .000 & - \\
\hline & $\mathbf{N}$ & 40 & 40 & 40 & 40 & 40 \\
\hline
\end{tabular}




\section{Egyptian}

Orthodontic Journal

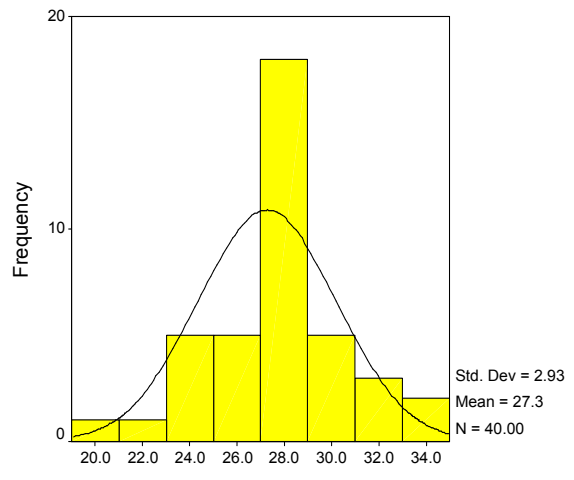

FMA

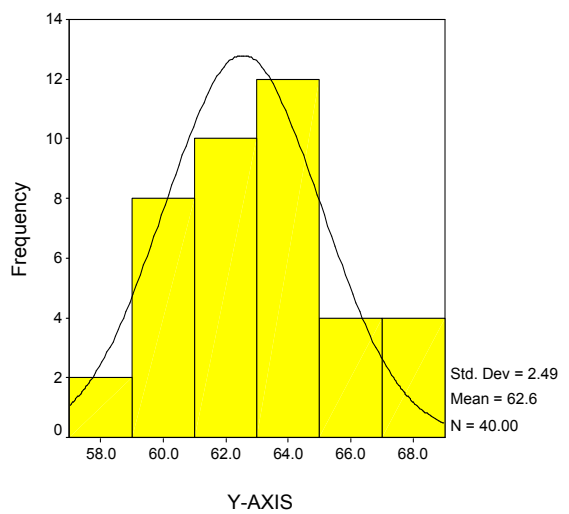

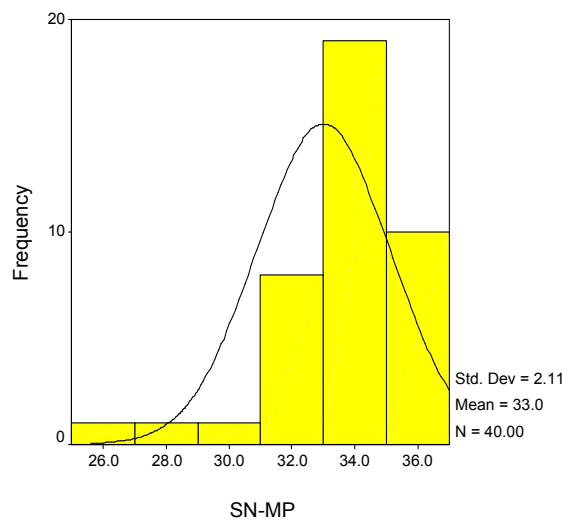

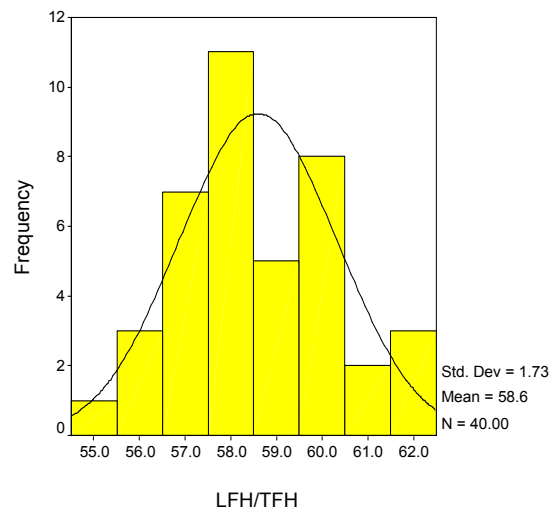

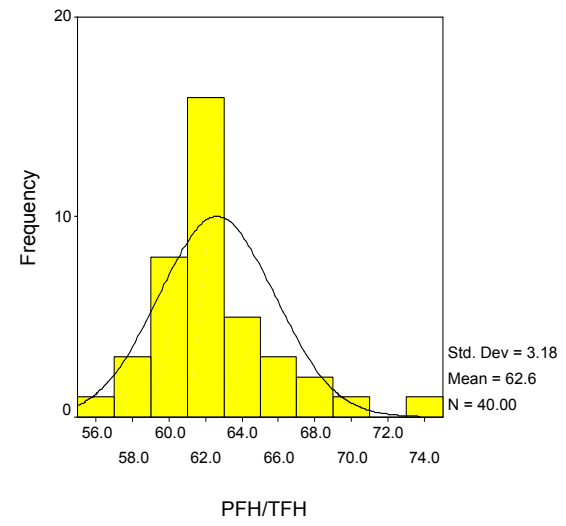

Figure 2. Histograms for the five vertical dimension measurements 


\section{Egyptian}

Orthodontic Journal
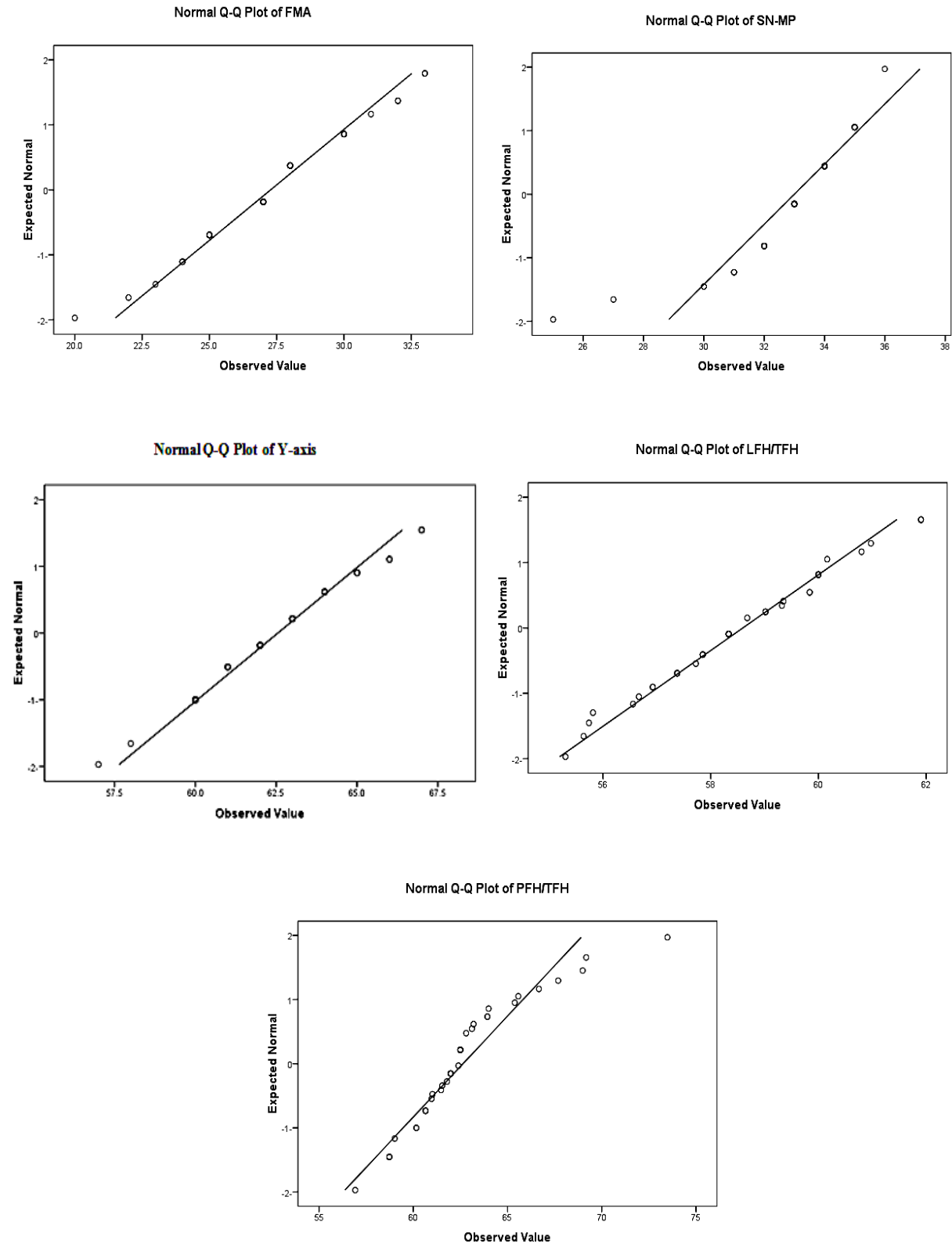

Figure 3. Q-Q probability plots for the five vertical dimension measurements 
Egyptian

Orthodontic Journal

\section{DISCUSSION}

Many angular, linear, and ratio measurements have been used in vertical dimension and open bite diagnosis. ${ }^{23-29}$ In the current study five measurements have been investigated; all tracings, landmarks identification, and measurements were carried out by the same investigator to avoid inter-observer variability adding to the measurements consistency. Results showed no systematic errors and reasonable casual errors. In clinical practice it is usually the difference between two cephalometric measurements that concerns the clinician, whether when comparing a cephalometric measurement with a "norm" or when comparing two cephalometric measurements. In order for the difference to be considered as significant it must exceed by a substantial margin the measurement error for that measure. Only then can one say with reasonable certainty that the observed difference is real and not simply the product of estimating errors. ${ }^{10}$ Therefore, acknowledging the accuracy and reliability of the cephalometric measurements is crucial for interpreting the results of cephalometric analyses. An estimation of 1 or 2 measuring units was regarded as of a clinical significane. ${ }^{21}$ The agreement between the first and second measurements in the current study was evaluated by the Dahlberg's formula, the casual errors were all almost within 1 measurement unit therefore, within the clinically accepted errors. The lowest errors were for $\mathrm{PFH} / \mathrm{TFH}$ followed by the $\mathrm{LFH} / \mathrm{TFH}$, ratios tend to decrease errors in measurements than linear or angular measurements. FMA and SN-MP showed similar casual errors less than 1 measurement unit. $\mathrm{Y}$ axis angle showed the highest casual error. The sources of errors could be errors of landmarks identification and/or errors of the measuring process. Low casual errors invite high reproducibility and reliability

It was considered during sample collection for the current study to include equal numbers of males and females to avoid bias in the data, the results of the student's t-test comparing the measurements of the two groups showed no significant difference between the two groups for any of the five measurements used and therefore subsequent statistics used the whole sample as one group. In the current study the FMA showed the best symmetry and clustering of the data distribution; with the highest 
Egyptian

Orthodontic Journal

frequencies for the central values between $26.5-27.5^{\circ}$ which is a range very close to the mean found to be $27.28 \pm 2.93^{\circ}$. This could be attributed to the familiarity and popularity of the FMA in orthodontic tracing as most or even all orthodontists have experience in using this angle. The LFH/TFH showed comparable symmetry and clustering of the data, the Q-Q probability plots (Figure 3) showed close distribution of the data around the straight line and the large duplications of the values were evident from the plots. On the other hand the histograms for the PFH-TFH (Figure 2) showed slight skewness to the left and evident stray of the data from the straight line of the Q-Q probability plots.

The histograms for the $\mathrm{Y}$-axis data (Figure 2) showed slight skewness to the left and the Q-Q probability plots (Figure 3) showed normal distribution of the data as indicated by the distribution of the values around the straight line. The histograms for the SN-MP angle (Figure 2) showed skewness to the right with the highest frequencies for the central values between $33.0^{\circ}$ and $35.0^{\circ}$ whereas the mean was $33.0^{\circ} \pm 2.11^{\circ}$ and the Q-Q probability plots (Figure 3) showed less clustering of the data around the straight line.

The three angular measurements showed moderate to high correlation and the two ratio measurements also showed moderate to high correlation. The only correlation between angular and ratio measurements was a moderate to high correlation between SN-MP angle and both $\mathrm{LFH} / \mathrm{TFH}$ and $\mathrm{PFH} / \mathrm{TFH}$ which can be explained by the shared cephalometric landmarks between them which consequently made the variables introducing measurement errors and variations less between these measurements. These results suggest that FMA is better confirmed by other angular measurements; LFH/TFH and PFH/TFH are better confirmed by the SN-MP angle.

\section{CONCLUSIONS}

- FMA and LFH/TFH showed more symmetrical and better clustering of the measurements.

- All five measurements showed causal errors within acceptable clinical level. 
- LFH/TFH showed the lowest casual errors while, Y-axis angle showed the highest causal error among all of the measurements.

- The results suggested that FMA is better confirmed by other angular measurements; LFH/TFH and PFH/TFH are better confirmed by the SN-MP angle.

\section{REFERENCES}

1- Broadbent BH. A new $\mathrm{x}$-ray technique and its application to orthodontia. Angle Orthod 1931;1:45-46.

2- Franchi L, Baccetti T, McNamara JA Jr. Cephalometric floating norms for north American adults. Angle Orthod. 1998;68:497-502.

3- Olmez H, Gorgulu S, Akin E, Bengi AO, Tekdemir I, Ors F. Measurement accuracy of a computer-assisted three-dimensional analysis and a conventional two-dimensional method. Angle Orthod. 2011;81:375-382.

4- Gribel BF, Gribel MN, Fraza o DC, McNamara JA Jr, Manzi FR. Accuracy and reliability of craniometric measurements on lateral cephalometry and 3D measurements on CBCT scans. Angle Orthod. 2011;81:26-35.

5- Chen YJ, Chin SK, Yao JC, Chang HF. The effects of differences in landmark identification on the cephalometric measurements in traditional versus digitized cephalometry. Angle Orthod 2004;74:155-161.

6- Major PW, Johnson DE, Hesse KL, Glover KE. Landmark identification error in posterior anterior cephalometrics. Angle Orthod 1994;64:447-454.

7- McWilliam JS, Welander U. The effect of image quality on the identification of cephalometric landmarks. Angle Orthod 1978;48:49-56.

8- Leonardi R, Annunziata A, Caltabiano M. Landmark identification error of posteroanterior cephalometric radiography, a systematic review. Angle Orthod 2008;78:761-765.

9- Baumrind S, Frantz RC. The reliability of head film measurements. Landmark identification. Am J Orthod. 1971;60:111-127. 
Egyptian

Orthodontic Journal

10- Baumrind S, Frantz RC. The reliability of head film measurements. Conventional angular and linear measures. Am J Orthod. 1971;60: 505-517.

11- Baumrind S, Miller D, Molthen R. The reliability of head film measurements. Tracing superimposition. Am J Orthod. 1976;70:617-644.

12- Richardson A. An investigation into the reproducibility of some points, planes and lines used in cephalometric analysis. Am J Orthod 1966:52:637-651.

13- Broch J, Slagsvold O, Rosler M. Error in landmark identification in lateral radiographic headplates. Eur J Orthod 1981;3:9-13.

14- Stabrun AE, Danielsen K. Precision in cephalometric landmark identification. Eur J Orthod 1982;4:185-196.

15- Phillips C, Greer J, Vig P, Matteson S. Photocephalometry: errors of projection and landmark location. Am J Orthod 1984;86:233-243.

16- Buschang PH, Tanguay R, Demirjian A. A full ANOVA model for the estimation of true and error variance. Angle Orthod 1987;57:168-175.

17- Savage AW, Showfety KJ, Yancey J. Repeated measures analysis of geometrically constructed and directly determined cephalometric points. Am J Orthod Dentofacial Orthop 1987;91:295-299.

18- Lim KF, Foong KW. Phosphor-stimulated computed cephalometry: reliability of landmark identification. Br J Orthod 1997;24:301-308.

19- Bruntz LQ, Palomo JM, Baden S, Hans MG. A comparison of scanned lateral cephalograms with corresponding original radiographs. Am J Orthod Dentofacial Orthop 2006;130:340-348.

20- Liu JK, Chen YT, cheng KS. Accuracy of computerized automatic identification of cephalometric landmarks. Am J Orthod Dentofacial Orthop 2000;118:535-540.

21- Damstra J, Huddleston slater JJR, fourie Z, Ren Y. Reliability and the smallest detectable differences of lateral cephalometric measurements. Am J Orthod Dentofacial Orthop 2010;138:546.e1-546.e.8.

22- Alexander J. Contemporary orthodontics. Carol Stream, IL: Quintessence Publishing Co, Inc; 1995. P. 77-85,116-117. 
23- Tweed $\mathrm{CH}$. The Frankfort-mandibular plane angle in orthodontic diagnosis, classification, treatment planning, and prognosis. Am J Orthod Oral Surg. $1946 ; 32: 175-230$.

24- Tweed $\mathrm{CH}$. Was the development of the diagnostic facial triangle as an accurate analysis based on fact or fancy? Am J Orthod. 1962;48:823-840.

25- Tweed $\mathrm{CH}$. The diagnostic facial triangle in the control of treatment objectives. Am J Orthod. 1969; 55:651-657.

26- Stuani AS, Matsumoto MA, Stuani MB.Cephalometric evaluation of patients with anterior open-bite. Braz Dent J. 2000;11:35-40.

27- Ibitayo AO, Pangrazio-Kulbersh V, Berger J, Bayirli B. Dentoskeletal effects of functional appliances vs bimaxillary surgery in hyperdivergent Class II patients. Angle Orthod. 2011;81:304-311.

28- Biggerstaff RH, Allen RC, Tuncay OC, Berkowitz J. A vertical cephalometric analysis of the human craniofacial complex. Am J Orthod. 1977;72:397-405.

29- Schendel SA, Eisenfeld J, Bell WH, Epker BN, Mishelevich DJ. The long face syndrome: vertical maxillary excess. Am J Orthod. 1976 Oct;70:398-408. 